\title{
Surface engineering of nanoporous substrate for solid oxide fuel cells with atomic layer-deposited electrolyte
}

\author{
Sanghoon $\mathrm{Ji}^{1}$, Waqas Hassan Tanveer ${ }^{2}$, Wonjong $\mathrm{Yu}^{2}$, Sungmin $\mathrm{Kang}^{3}$, Gu Young $\mathrm{Cho}^{2}$, \\ Sung Han $\mathrm{Kim}^{4}$, Jihwan $\mathrm{An}^{*} 5, \S$ and Suk Won Cha ${ }^{* 1,2, \pi}$
}

\section{Full Research Paper}

\section{Address:}

${ }^{1}$ Graduate School of Convergence Science and Technology, Seoul National University, lui-dong, Yeongtong-gu, Suwon 443-270, South Korea, ${ }^{2}$ Department of Mechanical Engineering, Seoul National University, Gwanak-ro, Gwanak-gu, Seoul 151-742, South Korea, ${ }^{3}$ Department of Mechanical Engineering, Korea Advanced Institute of Science and Technology, Daehak-ro, Yuseong- gu, Daejeon 305-701, South Korea, ${ }^{4}$ Corporate R\&D Institute, Samsung Electro Mechanics, Maeyoung-ro, Yeongtong-gu, Suwon 443-743, South Korea and ${ }^{5}$ Manufacturing Systems and Design Engineering Programme, Seoul National University of Science and Technology, Gongneung-ro, Nowon-gu, Seoul 139-743, South Korea

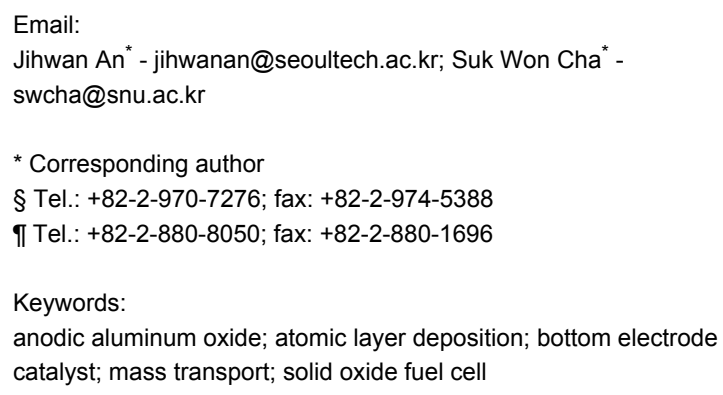

Beilstein J. Nanotechnol. 2015, 6, 1805-1810. doi:10.3762/bjnano.6.184

Received: 29 April 2015

Accepted: 09 August 2015

Published: 27 August 2015

Associate Editor: N. Motta

(c) $2015 \mathrm{Ji}$ et al; licensee Beilstein-Institut. License and terms: see end of document.

\begin{abstract}
Solid oxide fuel cells with atomic layer-deposited thin film electrolytes supported on anodic aluminum oxide (AAO) are electrochemically characterized with varying thickness of bottom electrode catalyst (BEC); BECs which are 0.5 and 4 times thicker than the size of AAO pores are tested. The thicker BEC ensures far more active mass transport on the BEC side and resultantly the thicker BEC cell generates $\approx 11$ times higher peak power density than the thinner BEC cell at $500{ }^{\circ} \mathrm{C}$.
\end{abstract}

\section{Introduction}

Recently solid oxide fuel cells with thin film ceramic electrolytes, called thin film solid oxide fuel cells (TF-SOFCs), have drawn attention as efficient power-generation devices delivering a satisfactory power density (above $1 \mathrm{~W} / \mathrm{cm}^{2}$ ) even below $600{ }^{\circ} \mathrm{C}$ stemming from the low ohmic resistance of thin film electrolytes [1,2]. However, their small active cell area resulted in insufficient output power, which required research on ways to enlarge the active cell area. In this regard, the use of scalable and porous substrates is one of the ways, among which anodic aluminum oxide (AAO) membranes are considered as 
prospective substrates due to their compatible thermal expansion properties with ceramic electrolytes, low corrosiveness, and easy manufacturing [3]. Furthermore, not containing any metallic particles, AAO substrates are advantageous on the thermo-mechanical durability compared to conventional substrate such as porous cermets [4].

Thin film electrolytes supported on porous substrates are generally vulnerable for pinhole issues causing gas permeation and electrode diffusion due to the rough surface of porous substrates [5]. This drawback necessitates conformal and dense thin film electrolytes, and can appreciably be relieved with an aid of atomic layer deposition (ALD) technique that is governed by binary reaction sequence chemistry in vacuum state [6]. Still, ALD-prepared electrolytes have rarely been utilized in porous substrate-supported SOFCs in spite of their superior characteristics; this was because the expectation that they could diminish the triple phase boundary (TPB), the meeting site between the electrolyte, the electrode, and the fuel, length and disturb the inflow of fuel at bottom electrode catalyst (BEC) side by excessive infiltration into the fuel channel $[7,8]$. Study on the thickness of the BEC, which could mitigate the infiltration issue, is therefore crucial in realizing the reliable TF-SOFC structure based on porous substrates such as AAO membranes.

In this study, the microstructural design of BECs in AAO supporting TF-SOFCs with ALD thin film electrolytes is discussed in terms of their impacts on the electrochemical performance of the cells. AAOs with $80 \mathrm{~nm}$-sized pores are used as substrates, and the thicknesses of BECs are smaller or larger than the size of AAO pores. Although the 320 nm-thick BEC cell has slightly worse reaction kinetics, compared to the $40 \mathrm{~nm}$-thick BEC cell, its peak power density is approximately
11 times higher due to far more active mass transport on the BEC side.

\section{Results and Discussion Highly dense ALD thin film electrolyte}

Thin films fabricated via low-temperature vacuum deposition techniques typically have lower packing density than powderprocessed thin films due to the presence of high density of grain-boundaries inside the thin films $[9,10]$. The density $\left(\approx 5.8 \mathrm{~g} / \mathrm{cm}^{3}\right)$ of yttria-stabilized zirconia (YSZ) thin films fabricated via ALD technique is, in like manner, lower than that $\left(\approx 6.1 \mathrm{~g} / \mathrm{cm}^{3}\right)$ of powder-processed YSZ [11]; nevertheless, the applied ALD process produced highly densified YSZ thin films compared to high-vacuum sputtering producing YSZ thin films with a density of $\approx 5.3 \mathrm{~g} / \mathrm{cm}^{3}$ (i.e., sputtering has been widely used for fabricating electrolytes for TF-SOFCs).

\section{Cell performance and microstructural analysis}

Because the AAO substrate used as a supporter for membrane electrode assembly is non-conductive and catalytically inactive, BEC needs to be coated on the AAO substrate prior to the electrolyte deposition for the anode side current collection and catalytic reaction. We considered the reaction kinetics at the BEC-electrolyte interface and fuel transport through AAO pores as the main design parameters in BEC coating.

To investigate the effects of BEC thickness on the electrochemical performance, polarization curves were plotted for 40, 320, and $480 \mathrm{~nm}$-thick BEC cells having $210 \mathrm{~nm}$-thick ALD YSZ electrolyte and $60 \mathrm{~nm}$-thick top electrode catalyst (used as cathode), referred to the Cell-A, Cell-B, and Cell-C (Figure 1). Three kinds of cells generates high open circuit voltages
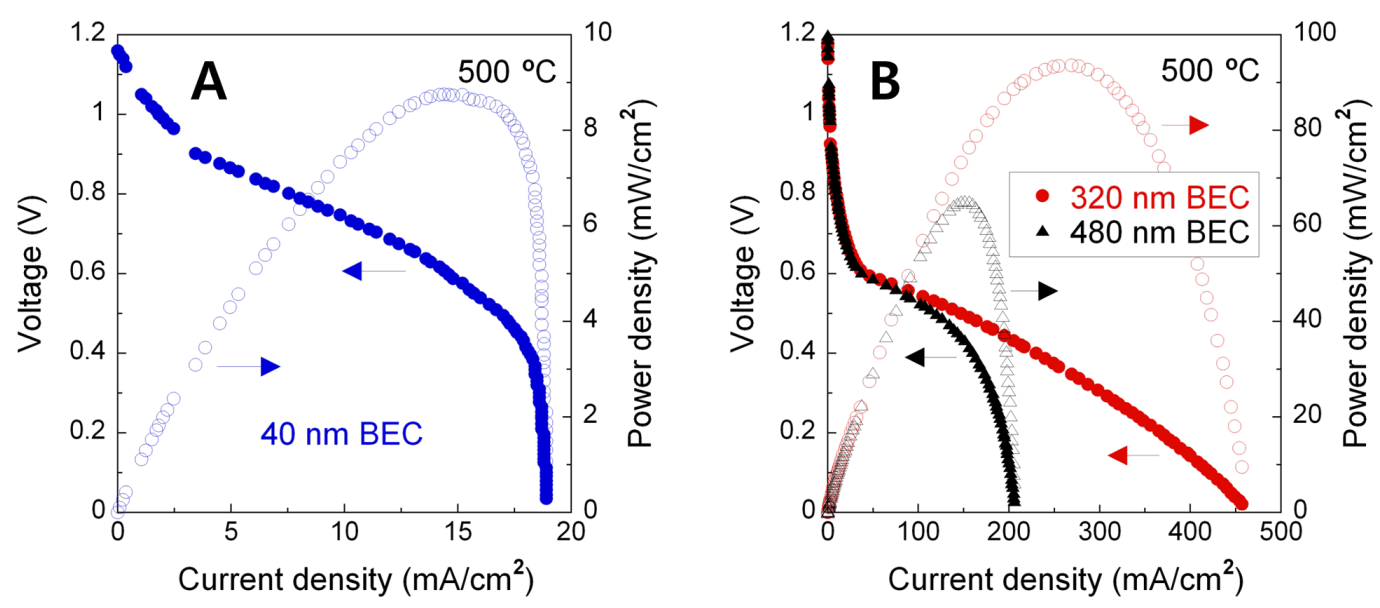

Figure 1: $I-V$ and power density curves, measured at $500^{\circ} \mathrm{C}$, for $80 \mathrm{~nm}$ pore AAO supporting (A) 40 , (B) 320 and $480 \mathrm{~nm}$-thick bottom electrode catalyst (BEC, sputtered Pt anode deposited under high-vacuum) solid oxide fuel cells, referred to the Cell-A, Cell-B and Cell-C, having $210 \mathrm{~nm}$-thick atomic layer-deposited (ALD) yttria-stabilized zirconia (YSZ) electrolyte and $60 \mathrm{~nm}$-thick top electrode catalyst (sputtered porous Pt cathode). 
(OCVs) of $\approx 1.17 \mathrm{~V}$ implying the high integrity of conformal and dense YSZ electrolytes, which is quite contiguous to the theoretical OCV value of $1.18 \mathrm{~V}$ under the operating conditions [12]. However, the overall voltage drop of the Cell-A with increasing current density is much bigger than that of the Cell-B, which results in a $\approx 11$ times lower peak power density $\left(8.8 \mathrm{~mW} / \mathrm{cm}^{2}\right)$ compared to that of Cell-B $\left(93.1 \mathrm{~mW} / \mathrm{cm}^{2}\right)$. In particular, as shown in Figure 1A, the voltage drop of the Cell-A at high current densities (near $\approx 19 \mathrm{~mA} / \mathrm{cm}^{2}$ ) is considerably sharp, which means that the Cell-A suffers from serious concentration loss compared to the Cell-B [13]. Owing to the prominent voltage drop at current densities above $100 \mathrm{~mA} / \mathrm{cm}^{2}$, the peak power density $\left(65.3 \mathrm{~mW} / \mathrm{cm}^{2}\right)$ of the Cell-C was somewhat smaller than that of the Cell-B (Figure 1B). This performance reduction may be due to the impoverished mass transport and shortened TPB length caused by excessively thick $\mathrm{BEC}$, which is parallel to previous research discussing the effects of the thickness and microstructure of BECs [14].

To examine the diffusion characteristics of ALD YSZ on the BEC side, $50 \mathrm{~nm}$-thick ALD YSZ was deposited on BECs with different thicknesses, whose cross-sectional microstructure was investigated by focused ion beam and field emission scanning electron microscopy (FIB/FE-SEM) imaging: the BECs were $40 \mathrm{~nm}$ and $320 \mathrm{~nm}$ in thickness. In case of the thinner BEC, a significant amount of ALD YSZ certainly infiltrates into the interior of the BEC as well as into AAO pores (the left image of Figure 2A), which may have negative impacts on fuel supply through AAO pores. In case of the thicker BEC, on the other hand, most of the conformal YSZ is deposited on the top surface of the BEC, as shown in the right image of Figure 2A. The thicker BEC could remarkably alleviate the infiltration of ALD YSZ into the interior of AAO pores. This pronounced difference in infiltration aspect of ALD YSZ should be closely linked to growth characteristics of sputtered films [12]. The thickness increase of physical vapor-deposited (PVD) films deposited on AAO pores expands their column-width and reduces the size of pinholes (or voids) existing in the sputtered films. We thus think that the merging of columnar grains of BEC according to the thickness increase lowers the infiltration degree of ALD YSZ into the BEC and AAO pores. This consideration is parallel to the interpretation from the $I-V$ analysis result of Figure 1 discussed in the previous section. Meanwhile, the existence of a few nanometer-sized pinholes formed throughout the thicker BEC, which could provide the physical space to diffuse $\mathrm{H}_{2}$ gas supplied to the anode side, implies the possibility of TPB formation on the BEC side (Figure 2B). The transmission electron microscopy and energy-dispersive $\mathrm{X}$-ray (TEM-EDX) quantitative analysis result in the middle of the thicker BEC (at dotted asterisk) verified the constituent elements of $\mathrm{Pt}$ (78.9\%), Zr (6.9\%), Y (0.5\%), and O (13.7\%), meaning that such pinholes were filled by the ALD YSZ.

Interestingly, the onset point of a voltage plateau for the Cell-B was as low as $0.6 \mathrm{~V}$ contrary to that of conventional SOFCs. This phenomenon is likely due to the remarkably large activation loss compared to other kinds of losses; the possible reasons for this deactivation are the insufficient electrocatalytic activity of the Pt BEC and the lack of TPB at the electrode-electrolyte interface $[15,16]$. The exchange current densities obtained by Tafel fitting were $0.43 \mathrm{~mA} / \mathrm{cm}^{2}$ and $0.29 \mathrm{~mA} / \mathrm{cm}^{2}$ for the Cell-A and Cell-B, respectively, as shown in Figure 3 [17]. Although the values were not significantly different each other, this fitting result indicates that the Cell-A may have somewhat longer TPB length at the BEC side and therefore faster reaction kinetics than the Cell-B, based on the interpretation described in related research $[18,19]$. One speculated reason of the longer TPB length for the Cell-A is that
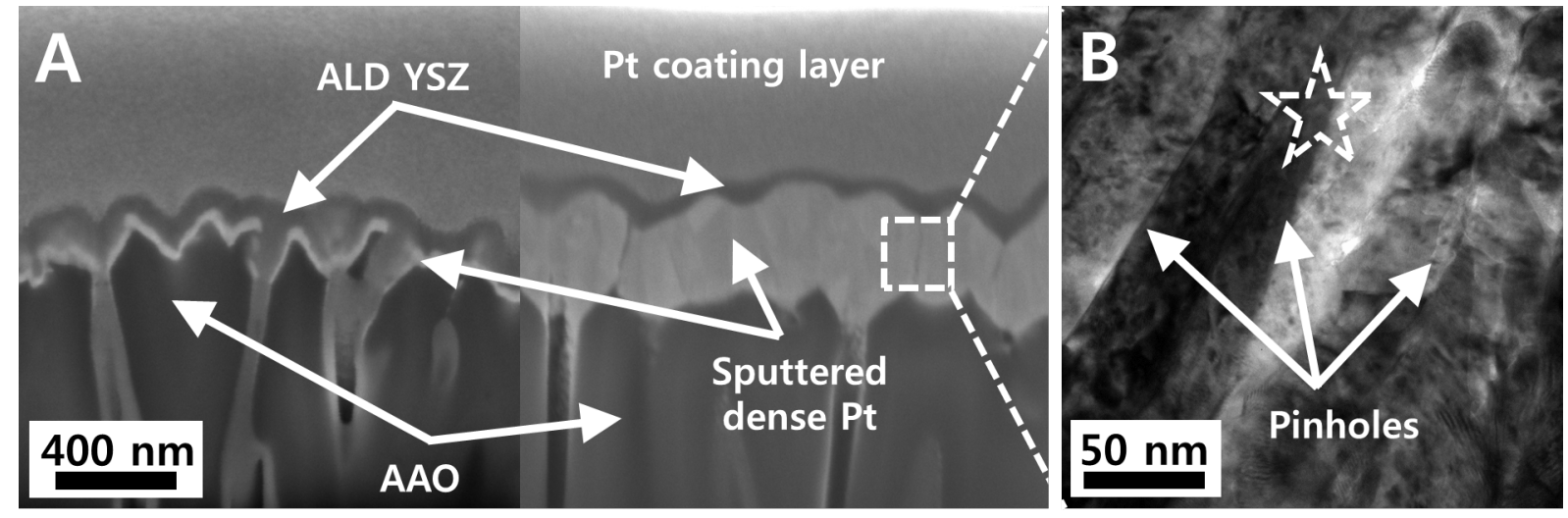

Figure 2: (A) Focused ion beam-prepared field emission scanning electron microscopy (FE-SEM) cross-sectional images for $50 \mathrm{~nm}$-thick ALD YSZ films deposited on $80 \mathrm{~nm}$ pore AAO supported 40 (left side) and 320 (right side) nm-thick BECs; (B) transmission electron microscopic image for $80 \mathrm{~nm}$ pore AAO supported $320 \mathrm{~nm}$-thick BEC. 


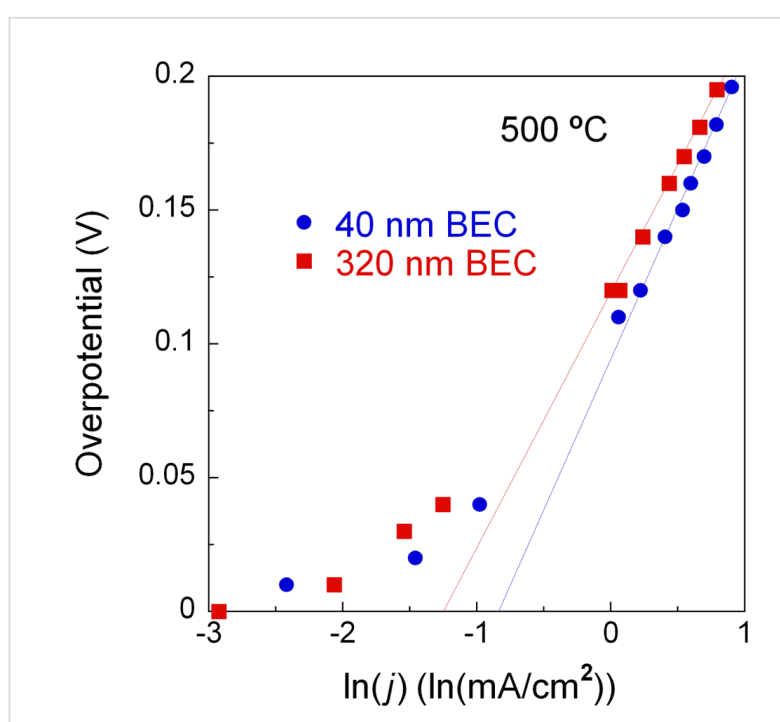

Figure 3: Tafel plots, measured at $500{ }^{\circ} \mathrm{C}$, for the Cell-A and Cell-B.

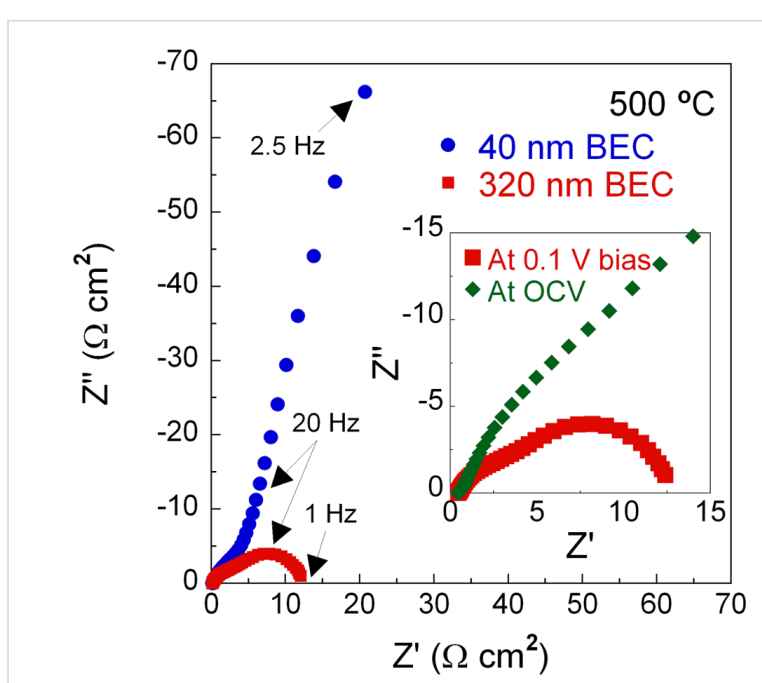

Figure 4: Electrochemical impedance spectroscopy analysis results, measured at $500{ }^{\circ} \mathrm{C}$, at bias voltage of $0.1 \mathrm{~V}$ for the Cell-A and Cell-B, and (inset) at open circuit voltage and bias voltage of $0.1 \mathrm{~V}$ for the Cell-B.

of constant phase element and resistance (related to electrode-electrolyte interfacial resistance) [6]. Referring to the previous literatures [6,20-22], it is considered that semicircles at higher and lower frequencies correspond to the anode and cathode interfacial resistances, respectively. The Cell-A, on the other hand, shows the EIS behavior with a diagonal form at a lower frequency region below $20 \mathrm{~Hz}$, which is not observed in the impedance spectra of Cell-B. This diagonal component is considered to the effect of Waburg element signifying a lack of active fuel supply [13]. This interpretation corresponds well to the above-mentioned polarization analysis, where we observed a sharp drop in the cell voltage of Cell-A at $j>\approx 19 \mathrm{~mA} / \mathrm{cm}^{2}$. The different shape of the semicircle around $20 \mathrm{~Hz}-$ which is regarded as the frequency time constant of cathode interfacial resistance [1] - of Cell-A compared with that of Cell-B seems to be due to the overlap of the cathode loop and the Warburg element. The high frequency intercept that corresponds to ohmic resistance is 0.5 and $0.45 \Omega \cdot \mathrm{cm}^{2}$ for the Cell-A and Cell-B, respectively. Considering both cells have similar cathode sheet resistance of $540-560 \Omega \cdot \mathrm{cm}$ and the electrolyte thickness is about the same, such a difference in ohmic resistance may be attributed to a difference in anode sheet resistance stemming from the different thicknesses. Nevertheless, this slight difference in ohmic resistance is immaterial to the peak power density of two cells (e.g., a voltage difference between the Cell-A and Cell-B is only $0.5 \mathrm{mV}$ at $10 \mathrm{~mA} / \mathrm{cm}^{2}$ that seems to be the range where the ohmic loss becomes dominant). Consequently, we think that the mass transport at the anode side needs to be considered as a dominant factor to determine the performance of AAO-supported TF-SOFCs with ALD thin film electrolyte as well as reaction kinetics and ohmic performance. 


\section{Experimental}

\section{Thin film fabrication}

ALD YSZ film was deposited with a showerhead-type plasmaenhanced ALD machine (Atomic Premium, CN1, South Korea) capable of accommodating one six-inch wafer with a radio frequency plasma generator. The processing chamber with a load-lock wafer handler was vacuumized using a dry pump to a base pressure of 2.7 $\mathrm{Pa}$. The temperature of the sample stage was set to $250{ }^{\circ} \mathrm{C}$. The detailed fabrication process of the YSZ film is presented in our previous work [23]. PVD YSZ and Pt films were deposited with a sputtering machine (A-Tech System, South Korea) equipped with a custom-designed rotating unit ensuring the high thickness uniformity; the rotating unit was revolved at $4 \mathrm{rpm}$. The target-to-substrate distance was $75 \mathrm{~mm}$, and the substrate was not heated. For deposition of the YSZ film, a gas mixture of $\mathrm{Ar}$ and $\mathrm{O}_{2}$ in the volumetric ratio of 80:20 was used. Background pressure was kept at 1.3 Pa during deposition. Radio frequency magnetron power of a sputtering gun was set to $50 \mathrm{~W}$. A two inch-sized YSZ disk pellet with an $8 \mathrm{~mol} \% \mathrm{Y}_{2} \mathrm{O}_{3}$ was used as the target. For deposition of the $\mathrm{Pt}$ film, 99.99\% purity Pt disk was used as the target. Porous Pt film (for cathode) and much denser Pt film (for anode, BEC) were deposited at $12 \mathrm{~Pa}$ and $0.7 \mathrm{~Pa}$, in an Ar gas atmosphere, respectively. The DC power of a sputtering gun was set to $200 \mathrm{~W}$, and the purity of Ar gas was $99.99 \%$. The fabrication processes of the Pt films are close to the ways described in our preview work [24].

\section{Thin film characterization}

The film density was determined by X-ray reflectometry analysis using the X'Pert Pro (PANalytical, Netherlands) instrument. The surface microstructure was investigated by FIB/FE-SEM analysis using the quanta 3D FEG (FEI Company, Netherlands) instrument. Local surface composition was measured by TEM-EDX analysis using the JEOL-2100F (JEOL, Japan) instrument. The characterization techniques utilized in this study are close to the measures described in our preview work [23].

\section{Electrochemical evaluation}

Commercial AAO (Synkera, USA) membrane with the thickness of $100 \mu \mathrm{m}$ and the pore size of $80 \mathrm{~nm}$, as shown in Figure 5, was used as the porous substrate to support TF-SOFCs. Test cells with an active electrode area of $1 \mathrm{~mm}^{2}$ were attached to the custom-designed gas feeding chamber using a ceramic adhesive (CP4010, Aremco Products, USA), which were heated to $500{ }^{\circ} \mathrm{C}$ with a ramping rate of $10{ }^{\circ} \mathrm{C} / \mathrm{min}$ using halogen heaters. $50 \mathrm{sccm}$ dry $\mathrm{H}_{2}$ gas was supplied to the anode side and the cathode was exposed to the atmospheric environment. The anode was connected with a combination of silver paste (597A, Aremco Products, Inc., USA) and a

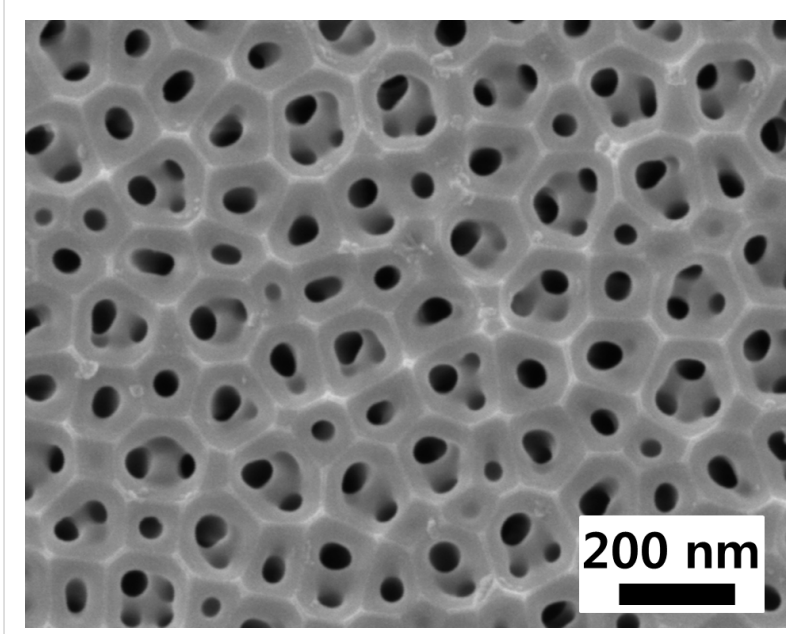

Figure 5: FE-SEM top-view image of AAO membrane with wellarrayed $80 \mathrm{~nm}$-sized pores, cleaned by sonication in ethanol.

$0.5 \mathrm{~mm}$-thick silver wire, while the cathode was contacted using a hardened-steel tip with a radius of $0.19 \mathrm{~mm}$ probe moved by a $\mathrm{XYZ}$ stage. Electrochemical characterization was performed in the two-electrode configuration without a reference electrode. EIS analysis was carried out using an electrochemical testing system (1287/1260, Solatron Analytical, UK), in which the alternating current amplitude was set to $50 \mathrm{mV}$. The testing method is close to the way presented in our preview work [6].

\section{Conclusion}

We discussed about the preliminary design of BEC for porous AAO supporting TF-SOFCs with conformal and dense thin film electrolyte prepared by ALD technique. The thickness of BEC had a significant impact on the infiltration degree of ALD electrolyte into the BEC and the AAO substrate. The infiltration degree of ALD electrolyte moderated when the thicker BEC was employed, which led to the generation of appreciably higher peak power density caused by more active mass transport on the BEC side. Such thicker BEC improved current collecting performance to some degree; however, resulted in slightly slower reaction kinetics. Further optimization of BEC thickness may enhance the cell performance, which could lead to wider potential applications of AAO supporting TF-SOFCs as high-efficiency power sources. In addition, the discussion presented in this paper may help to design high-performance porous substrate-supported TF-SOFCs with few hundred nanometer-thick BECs.

\section{Acknowledgements}

This work was supported by the New \& Renewable Energy Development Program of the Korea Institute of Energy Technology Evaluation and Planning (KETEP) grant funded by the 
Korea government Ministry of Knowledge Economy (No. 20113020030010).

\section{References}

1. An, J.; Kim, Y.-B.; Park, J.; Gür, T. M.; Prinz, F. B. Nano Lett. 2013, 13, 4551-4555. doi:10.1021/nl402661p

2. Choi, S. H.; Hwang, C. S.; Lee, M. H. ECS Electrochem. Lett. 2014, 3, F57-F59. doi:10.1149/2.0011409eel

3. Park, Y.-i.; Cha, S.-w.; Saito, Y.; Prinz, F. B. Thin Solid Films 2005, 476, 168-173. doi:10.1016/j.tsf.2004.09.059

4. Faes, A.; Hessler-Wyser, A.; Presvytes, D.; Vayenas, C. G.; Van Herle, J. Fuel Cells 2009, 6, 841-851. doi:10.1002/fuce.200800147

5. Ji, S.; Chang, I.; Lee, Y. H.; Lee, M. H.; Cha, S. W. Thin Solid Films 2013, 539, 117-121. doi:10.1016/j.tsf.2013.05.063

6. Ji, S.; Chang, I.; Cho, G. Y.; Lee, Y. H.; Shim, J. H.; Cha, S. W. Int. J. Hydrogen Energy 2014, 39, 12402-12408. doi:10.1016/j.ijhydene.2014.02.081

7. Kwon, C.-W.; Son, J.-W.; Lee, J.-H.; Kim, H.-M.; Lee, H.-W.; Kim, K.-B. Adv. Funct. Mater. 2011, 21, 1154-1159. doi:10.1002/adfm.201002137

8. Cassir, M.; Ringuedé, A.; Niinistö, L. J. Mater. Chem. 2010, 20, 8987-8993. doi:10.1039/c0jm00590h

9. Shim, J. H.; Chao, C.-C.; Hunag, H.; Prinz, F. B. Chem. Mater. 2007, 19, 3850-3854. doi:10.1021/cm070913t

10. Hausmann, D. M.; Kim, E.; Becker, J.; Gordon, R. G. Chem. Mater. 2002, 14, 4350-4358. doi:10.1021/cm020357x

11. Will, J.; Mitterdorfer, A.; Kleinlogel, C.; Perednis, D.; Gauckler, L. J. Solid State lonics 2000, 131, 79-96. doi:10.1016/S0167-2738(00)00624-X

12. Liu, M.; Ding, D.; Bai, Y.; He, T.; Liu, M. J. Electrochem. Soc. 2012, 159, B661-B665. doi:10.1149/2.032206jes

13. Smith, J. R.; Chen, A.; Gostovic, D.; Hickey, D.; Kundinger, D.; Duncan, K. L.; DeHoff, R. T.; Jones, K. S.; Wachsman, E. D. Solid State lonics 2009, 180, 90-98. doi:10.1016/j.ssi.2008.10.017

14. Park, J.; Lee, Y.; Chang, I.; Lee, W.; Cha, S. W. Thin Solid Films 2015, 584, 125-129. doi:10.1016/j.tsf.2014.11.018

15. Hibino, T.; Hashimoto, A.; Suzuki, M.; Sano, M. J. Electrochem. Soc. 2002, 149, A1503-A1508. doi:10.1149/1.1513983

16. An, J.; Kim, Y.-B.; Prinz, F. B. Phys. Chem. Chem. Phys. 2013, 15, 7520-7525. doi:10.1039/c3cp50996f

17. Takagi, Y.; Kian, K.; Ko, C.; Ramanathan, S. J. Power Sources 2013, 243, 1-9. doi:10.1016/j.jpowsour.2013.06.002

18. Harada, T.; Jin, Y. C.; Heo, P.; Hibino, T. Fuel Cells 2010, 10, 798-803. doi:10.1002/fuce.200900162

19. Jin, Y. C.; Okada, M.; Hibino, T. J. Power Sources 2011, 196, 4905-4910. doi:10.1016/j.jpowsour.2011.02.028

20. Park, J. S.; Holme, T. P.; Shim, J. H.; Prinz, F. B. MRS Commun. 2012, 2, 107-111. doi:10.1557/mrc.2012.18

21. Ha, S.; Su, P.-C.; Cha, S.-W. J. Mater. Chem. A 2013, 1, 9645-9651. doi:10.1039/c3ta11758h

22. Yu, W.; Ji, S.; Cho, G. Y.; Noh, S.; Tanveer, W. H.; An, J.; Cha, S. W. J. Vac. Sci. Technol., A 2015, 33, 01A145. doi:10.1116/1.4904206

23. Ji, S.; Cho, G. Y.; Yu, W.; Su, P.-C.; Lee, M. H.; Cha, S. W. ACS Appl. Mater. Interfaces 2015, 7, 2998-3002. doi:10.1021/am508710s

24. Ji, S.; Chang, I.; Lee, Y. H.; Park, J.; Paek, J. Y.; Lee, M. H.; Cha, S. W. Nanoscale Res. Lett. 2013, 8, 48. doi:10.1186/1556-276X-8-48

\section{License and Terms}

This is an Open Access article under the terms of the Creative Commons Attribution License

(http://creativecommons.org/licenses/by/2.0), which permits unrestricted use, distribution, and reproduction in any medium, provided the original work is properly cited.

The license is subject to the Beilstein Journal of Nanotechnology terms and conditions: (http://www.beilstein-journals.org/bjnano)

The definitive version of this article is the electronic one which can be found at:

doi:10.3762/bjnano.6.184 